\title{
Protecting Retailers Against Contagion: Exploring the Shielding Role of Marketing in the Negative Spillover of the Target Customer Data Breach
}

\author{
Saim Kashmiri, Cameron Duncan Nicol, and Liwu Hsu
}

\begin{abstract}
The authors examine the effect of a major customer data breach at a US retail firm on the market value of other US retailers. Using the massive breach at Target Corporation in the year 2013 as their empirical context, the authors discover the existence of a strong industry-wide contagion effect; the results from an event study of 168 publicly listed US retail firms indicate that the Target breach resulted in negative abnormal returns for other US retailers. The authors also explore the role played by marketing factors in insulating some retailers from this contagion effect. They find empirical evidence that retailers where the marketing function held a high degree of influence in the top management team (TMT), those with strong marketing capabilities, and those with strong corporate social performance (CSP), experienced less negative abnormal returns surrounding the news of the Target breach. These results highlight the shielding benefit that strong marketing resources and high corporate citizenship provide to retailers in the backdrop of an industry counterpart's customer data breach.
\end{abstract}

\footnotetext{
S. Kashmiri $(\bowtie) \cdot$ C.D. Nicol

University of Mississippi, University, MS, USA

e-mail: skashmiri@bus.olemiss.edu; cnicol@bus.olemiss.edu

L. Hsu

University of Alabama in Huntsville, Huntsville, AL, USA

e-mail: liwu.hsu@uah.edu
} 